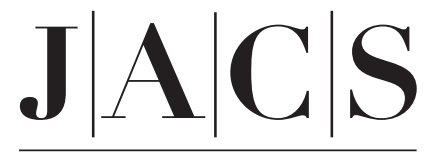

A R T I C L E S

Published on Web 05/10/2006

\title{
Solid-State NMR Study of the Transformation of Octacalcium Phosphate to Hydroxyapatite: A Mechanistic Model for Central Dark Line Formation
}

\author{
Yao-Hung Tseng, ${ }^{\dagger}$ Chung-Yuan Mou, ${ }^{\dagger, \ddagger}$ and Jerry C. C. Chan ${ }^{\star, \dagger}$ \\ Contribution from the Department of Chemistry and the Center of Condensed Matter, National
}

Taiwan University, No. 1, Section 4, Roosevelt Road, Taipei, Taiwan

Received January 17, 2006; E-mail: chanjcc@ntu.edu.tw

\begin{abstract}
For many years, octacalcium phosphate (OCP) has been postulated as the precursor phase of biological apatite in bones and teeth. In this work, we study the molecular mechanism of OCP to hydroxyapatite (HAp) transformation in vitro by several physical techniques, with particular emphasis on solid-state ${ }^{31} \mathrm{P}$ homonuclear double-quantum (DQ) NMR spectroscopy. The in vitro system is prepared by mixing urea, sodium phosphate monobasic dehydrate, and calcium nitrate tetrahydrate at $100{ }^{\circ} \mathrm{C}$. The images obtained by scanning electron microscopy and transmission electron microscopy show that the bladelike OCP crystals will transform into hexagonal rod-shaped HAp crystals as the $\mathrm{pH}$ of the reaction mixture increases slowly from 4.35 to 6.69 in $12 \mathrm{~h}$. Powder X-ray diffraction patterns indicate that a trace amount of monetite was also precipitated when the $\mathrm{pH}$ was around 5. Together with computer-assisted lattice matching, our DQ NMR data reveal that OCP crystals transform to HAp topotaxially, where the $[000 \overline{1}]_{\text {HAp }}$ and $[2 \overline{1} 10]_{\text {HAp }}$ axes are along the same directions as the [001] OCP and [010] OCP axes, respectively. On the basis of our in vitro results, the formation of the central dark line commonly found in biological hard tissues could be explained by the inherent lattice mismatch between OCP and HAp. Furthermore, the data of the ${ }^{31} \mathrm{P}\left\{{ }^{1} \mathrm{H}\right\}$ cross-polarization NMR suggest that water molecules enter the hydration layers of OCP crystals via the hydrolysis reaction $\mathrm{HPO}_{4}{ }^{2-}+\mathrm{OH}^{-}=\mathrm{PO}_{4}{ }^{3-}+\mathrm{H}_{2} \mathrm{O}$, which also accounts for the deprotonation of the $\mathrm{HPO}_{4}{ }^{2-}$ ions during the transformation.
\end{abstract}

\section{Introduction}

Biomineralization is a biological process describing the formation of minerals in living organisms. ${ }^{1}$ Calcium phosphates are the major inorganic constituents of biological hard tissues in vertebrates, existing in a form with close resemblance to hydroxyapatite $\left.\left(\mathrm{HAp}, \mathrm{Ca}_{10}\left(\mathrm{PO}_{4}\right)_{6}(\mathrm{OH})_{2}\right)\right)^{2,3}$ The so-called biological apatite or dahllite refers to poorly crystallized nonstoichiometric carbonate-containing HAp. Whether biological apatite is formed by direct precipitation or through an intermediate phase remains an unsettled issue in the field of biomineralization. ${ }^{2,4}$ Because of the structural similarity between HAp and octacalcium phosphate $\left(\mathrm{OCP}, \mathrm{Ca}_{8} \mathrm{H}_{2}\left(\mathrm{PO}_{4}\right)_{6} \cdot 5 \mathrm{H}_{2} \mathrm{O}\right)$, OCP has been hypothesized as the precursor phase of biological apatite. ${ }^{5}$ The most compelling evidence for this hypothesis is the observation of an OCP "central dark line" (CDL) in many biological apatites and in some synthetically prepared HAp. ${ }^{6-8}$

\footnotetext{
$\dagger$ Department of Chemistry.

Center of Condensed Matter.

(1) Mann, S. Biomineralization-Principles and Concepts in Bioinorganic Materials Chemistry; Oxford University Press: New York, 2001

(2) Dorozhkin, S. V.; Epple, M. Angew. Chem., Int. Ed. 2002, 41, 3130.

(3) LeGeros, R. Z. Calcium Phosphates in Oral Biology and Medicine; Karger: Basel, 1991.

(4) Iijima, M.; Moradian-Oldak, J. J. Mater. Chem. 2004, 14, 2189.

(5) Brown, W. E. Clin. Orthop. 1966, 44, 205.

(6) Iijima, M.; Nelson, D. G. A.; Pan, Y.; Kreinbrink, A. T.; Adachi, M.; Goto, T.; Moriwaki, Y. Calcif. Tissue Int. 1996, 59, 377.

(7) Bodier-Houlle, P.; Steuer, P.; Voegel, J. C.; Cuisinier, F. J. G. Acta Crystallogr. D 1998, 54, 1377.
}

10.1021/ja060336u CCC: $\$ 33.50$ @ 2006 American Chemical Society
In enamel crystallites of fossil animals, the microstructure of HAp crystals containing lattice images of CDLs appears stable during long geological periods. ${ }^{9}$ Although it is a consensus that a CDL is a consequence of incomplete hydrolysis of OCP, the molecular mechanism of its formation is basically unknown.

OCP is thermodynamically less stable than hydroxyapatite, and it is often found as an intermediate phase during the precipitation of HAp. ${ }^{10,11}$ Many in vitro studies of calcium phosphate precipitation have been carried out to elucidate the dependence of the thermodynamic events and the crystal morphology on the degree of supersaturation, ${ }^{12}$ temperature, ${ }^{13,14}$ $\mathrm{pH}$ conditions, ${ }^{15,16}$ and the rate of precipitation. ${ }^{17-24}$ The most

(8) Aoba, T.; Komatsu, H.; Shimazu, Y.; Yagishita, H.; Taya, Y. Connect. Tissue Res. 1998, 39, 129.

(9) Kakei, M.; Nakahara, H.; Kumegawa, M.; Mishima, H.; Kozawa, Y. J. Dent. Res. 2001, 80, 1560.

(10) Nancollas, G. H.; Tomazic, B. J. Phys. Chem. 1974, 78, 2218.

(11) Eanes, E. D.; Meyer, J. L. Calcif. Tissue Res. 1977, 23, 259.

(12) Boskey, A. L.; Posner, A. S. J. Phys. Chem. 1976, 80, 40.

(13) Chickerur, N. S.; Tung, M. S.; Brown, W. E. Calcif. Tissue Int. 1980, 32 55 .

(14) Nelson, D. G. A.; McLean, J. D. Calcif. Tissue Int. 1984, 36, 219.

(15) Eanes, E. D.; Posner, A. S. Mater. Res. Bull. 1970, 5, 377.

(16) Iijima, M.; Kamemizu, H.; Wakamatsu, N.; Goto, T.; Doi, Y.; Moriwaki, Y. J. Cryst. Growth 1997, 181, 70.

(17) Kniep, R.; Busch, S. Angew. Chem., Int. Ed. Engl. 1996, 35, 2624.

(18) Iijima, M.; Moriwaki, Y.; Yamaguchi, R.; Kuboki, Y. Connect. Tissue Res 1997, 36, 73

(19) Schwarz, K.; Epple, M. Chem.-Eur. J. 1998, 4, 1898.

(20) Busch, S.; Dolhaine, H.; DuChesne, A.; Heinz, S.; Hochrein, O.; Laeri, F.; Podebrad, O.; Vietze, U.; Weiland, T.; Kniep, R. Eur. J. Inorg. Chem. 1999, 1643 
informative results hitherto reported were obtained from X-ray powder diffraction (XRD), scanning electron microscopy (SEM), and transmission electron microscopy (TEM). ${ }^{4}$ OCP can be described as an alternating layer structure of an apatite layer and a hydrated layer, ${ }^{25}$ where the apatite layer is structurally very similar to HAp. ${ }^{26,27}$ According to the OCP precursor model proposed by Brown, ${ }^{5}$ the first calcium phosphate crystals formed in a supersaturated solution under physiological conditions are OCP-like. The subsequent hydrolysis step leads to the formation of HAp, where the $[0001]_{\text {HAp }}$ and $[\overline{1} 2 \overline{1} 0]_{\text {HAp }}$ axes are along the same directions as the $[001]_{\mathrm{OCP}}$ and $[010]_{\mathrm{OCP}}$ axes, respectively, during the structural transition. Although this model is consistent with the results of some TEM studies, ${ }^{28,29}$ a recent computational study shows that the $[0001]_{\mathrm{HAp}}$ and $[001]_{\mathrm{OCP}}$ axes should be at opposite directions to minimize the free energy at the interface between OCP and HAp. ${ }^{30}$ It is by no means trivial to verify this computational prediction experimentally because TEM results cannot distinguish the alignment of two crystallographic axes from parallel to antiparallel fashion. Furthermore, OCP is meta-stable and it will appear only if the $\mathrm{pH}$ in the crystallization system is below 6. In our previous work, we developed an in vitro system to realize a single-crystal-single-crystal transformation from OCP to HAp in the presence of gelatin and urea. ${ }^{31}$ The transformation of OCP to HAp is initiated by raising the $\mathrm{pH}$ condition from acidic to alkaline. Because a uniform $\mathrm{pH}$ increase of the reaction mixture is achieved by slow decomposition of urea at $100{ }^{\circ} \mathrm{C}$, our in vitro system is an ideal model system for the study of the molecular mechanism of the OCP to HAp transition. Although all the phosphorus atoms in a unit cell of HAp are equivalent, there are six crystallographically nonequivalent phosphorus sites in OCP. As such, solid-state ${ }^{31} \mathrm{P}$ NMR is well suited to characterize the OCP to HAp transformation at the molecular level.

The high-resolution ${ }^{31} \mathrm{P}$ NMR studies of OCP can be dated back to the $1980 \mathrm{~s},{ }^{32,33}$ and the complete spectral assignment has been made very recently. ${ }^{34,35}$ Throughout the years, a large variety of advanced NMR techniques such as ${ }^{31} \mathrm{P}\left\{{ }^{1} \mathrm{H}\right\}$ crosspolarization $(\mathrm{CP})$ at variable contact delays, ${ }^{32}$ dipolar dephasing techniques, ${ }^{33}$ heteronuclear correlation spectroscopy (HETCOR), ${ }^{36-38}$ differential cross-polarization, ${ }^{39,40}$ and multi-

(21) Falini, G.; Gazzano, M.; Ripamonti, A. J. Mater. Chem. 2000, 10, 535.

(22) Iijima, M.; Moriwaki, Y.; Takagi, T.; Moradian-Oldak, J. J. Cryst. Growth 2001, 222, 615 .

(23) Peters, F.; Epple, M. J. Chem. Soc., Dalton Trans. 2001, 3585.

(24) Iijima, M.; Moriwaki, Y.; Wen, H. B.; Fincham, A. G.; Moradian-Oldak, J. J. Dent. Res. 2002, 81, 69.

(25) Brown, W. E. Nature (London) 1962, 196, 1048

(26) Kay, M. I.; Young, R. A.; Posner, A. S. Nature (London) 1964, 204, 1050

(27) Mathew, M.; Brown, W. E.; Schroeder, L. W.; Dickens, B. J. Crystallogr. Spectrosc. Res. 1988, 18, 235.

(28) Suvorova, E. I.; Madsen, H. E. L. J. Cryst. Growth 1999, 199, 677.

(29) Iijima, M.; Tohda, H.; Moriwaki, Y. J. Cryst. Growth 1992, 116, 319.

(30) Fernandez, M. E.; Zorrilla-Cangas, C.; Garcia-Garcia, R.; Ascencio, J. A.; Reyes-Gasga, J. Acta Crystallogr. 2003, B59, 175.

(31) Zhan, J.; Tseng, Y.-H.; Chan, J. C. C.; Mou, C.-Y. Adv. Funct. Mater. 2005, 15, 2005.

(32) Rothwell, W. P.; Waugh, J. S.; Yesinowski, J. P. J. Am. Chem. Soc. 1980, 102, 2637.

(33) Aue, W. P.; Roufosse, A. H.; Glimcher, M. J.; Griffin, R. G. Biochemistry 1984, 23, 6110 .

(34) Tseng, Y. H.; Zhan, J. H.; Lin, K. S. K.; Mou, C. Y.; Chan, J. C. C. Solid State Nucl. Magn. Reson. 2004, 26, 99.

(35) Tseng, Y. H.; Mou, Y.; Mou, C. Y.; Chan, J. C. C. Solid State Nucl. Magn. Reson. 2005, 27, 266.

(36) Santos, R. A.; Wind, R. A.; Bronnimann, C. E. J. Magn. Reson., Ser. B 1994, 105, 183

(37) Kaflak-Hachulska, A.; Samoson, A.; Kolodziejski, W. Calcif. Tissue Int 2003, 73, 476

(38) Cho, G. Y.; Wu, Y. T.; Ackerman, J. L. Science 2003, 300, 1123. nuclear double-resonance techniques ${ }^{41,42}$ have been successfully used to characterize the structures of synthetic hydroxyapatite, calcified tissues, and apatite formation. Therefore, in the present study, we chose to use a series of solid-state ${ }^{31} \mathrm{P}$ NMR techniques including ${ }^{31} \mathrm{P}\left\{{ }^{1} \mathrm{H}\right\}$ Lee-Goldburg spectroscopy ${ }^{43,44}$ and ${ }^{31} \mathrm{P}$ homonuclear double-quantum (DQ) $\mathrm{NMR}^{45}$ to monitor the OCP to HAp transition. The in vitro system we developed earlier, in the absence of gelatin, is used to prepare calcium phosphate precipitated at different $\mathrm{pH}$ conditions. From the DQ NMR measurements, we are able to show that the $[000 \overline{1}]_{\text {HAp }}$ and $[2 \overline{1} 10]_{\text {HAp }}$ axes are along the same directions as the $[001]_{\text {OCP }}$ and $[010]_{\text {OCP }}$ axes, respectively. That is, the $c$ axes of the OCP and HAp unit cells are oppositely aligned at the interface. Consequently, we suggest an explanation for the formation of CDLs in biological hard tissues based on the inherent lattice mismatch between OCP and HAp. Furthermore, the data of the ${ }^{31} \mathrm{P}\left\{{ }^{1} \mathrm{H}\right\}$ cross-polarization NMR indicate that water molecules enter the hydration layers of OCP crystals via the hydrolysis reaction $\mathrm{HPO}_{4}{ }^{2-}+\mathrm{OH}^{-}=\mathrm{PO}_{4}{ }^{3-}+\mathrm{H}_{2} \mathrm{O}$, which also accounts for the deprotonation of the $\mathrm{HPO}_{4}{ }^{2-}$ ions during the transformation. Overall, our NMR data provide hitherto the most detailed description of the OCP to HAp transformation mechanism at the molecular level.

\section{Experimental Section}

Sample Preparation and Characterization. Urea (99.5\%), sodium phosphate monobasic dehydrate $\left(\mathrm{H}_{2} \mathrm{NaPO}_{4} \cdot 2 \mathrm{H}_{2} \mathrm{O}\right)(99 \%)$, and calcium nitrate tetrahydrate $\left(\mathrm{Ca}\left(\mathrm{NO}_{3}\right)_{2} \cdot 4 \mathrm{H}_{2} \mathrm{O}\right)(99 \%)$ were used as received (Acros). A mixture of $10 \mathrm{mmol}$ of $\mathrm{Ca}\left(\mathrm{NO}_{3}\right)_{2} \cdot 4 \mathrm{H}_{2} \mathrm{O}, 10 \mathrm{mmol}$ of $\mathrm{H}_{2}$ $\mathrm{NaPO}_{4} \cdot 2 \mathrm{H}_{2} \mathrm{O}$, and $20 \mathrm{mmol}$ of urea was dissolved in $400 \mathrm{~mL}$ of doubly distilled water and then sealed in a polypropylene container. The aqueous solution was kept at $100{ }^{\circ} \mathrm{C}$ for different time periods. The precipitates thus obtained were filtered, washed, and then dried at 60 ${ }^{\circ} \mathrm{C}$ for 1 day. The $\mathrm{pH}$ of the filtrate was measured at room temperature. A series of samples were obtained at different reaction times, viz. 1.5, $3,4,5,6,7,9,12$, and $96 \mathrm{~h}$. All the samples will henceforth be labeled on the basis of their reaction times. X-ray diffraction analysis was performed on a Philips X'Pert diffractometer, using $\mathrm{Cu} \mathrm{K} \alpha$ radiation $(\lambda=1.5418 \AA)$. Determination of lattice parameters was done by the software EXPGUI. ${ }^{46,47}$ The field emission SEM was taken on a JEOLJSM-6700F field emission scanning electron microscope operated at $10 \mathrm{kV}$. The TEM and electron diffraction (ED) patterns were taken on Hitachi S-7100 and Philips FEI Tecnai $20 \mathrm{G}^{2}$ instruments operating at 75 and $200 \mathrm{kV}$, respectively.

Solid-State NMR. All NMR experiments were carried out at ${ }^{31} \mathrm{P}$ and ${ }^{1} \mathrm{H}$ frequencies of 121.5 and $300.1 \mathrm{MHz}$, respectively, on a Bruker DSX300 NMR spectrometer equipped with a commercial 4-mm probe. All spectra were measured at room temperature. The sample was confined to the middle one-third of the rotor volume using Teflon spacers. The variation of magic-angle spinning (MAS) frequency was

(39) Wu, Y.; Ackerman, J. L.; Strawich, E. S.; Rey, C.; Kim, H. M.; Glimcher, M. J. Calcif. Tissue Int. 2003, 72, 610.

(40) Isobe, T.; Nakamura, S.; Nemoto, R.; Senna, M.; Sfihi, H. J. Phys. Chem. $B$ 2002, 106, 5169 .

(41) Chan, J. C. C.; Ohnsorge, R.; Meise-Gresch, K.; Eckert, H.; Holand, W.; Rheinberger, V. Chem. Mater. 2001, 13, 4198

(42) Lin, K. S. K.; Tseng, Y. H.; Mou, Y.; Hsu, Y. C.; Yang, C. M.; Chan, J. C. C. Chem. Mater. 2005, 17, 4493 .

(43) van Rossum, B. J.; de Groot, C. P.; Ladizhansky, V.; Vega, S.; de Groot, H. J. M. J. Am. Chem. Soc. 2000, $122,3465$.

(44) Ladizhansky, V.; Vega, S. J. Chem. Phys. 2000, 112, 7158.

(45) Ernst, R. R.; Bodenhausen, G.; Wokaun, A. Principles of Nuclear Magnetic Resonance in One and Two Dimensions; Clarendon Press: Oxford, 1987.

(46) Larson, A. C.; von Dreele, R. B. Los Alamos National Laboratory Report LA-UR; 2000; pp 86-748.

(47) Toby, B. H. J. Appl. Crystallogr. 2001, 34, 210. 
Table 1. Summary of the $\mathrm{pH}$ Values of the Reaction Mixture at Different Periods

\begin{tabular}{cc}
\hline reaction time $(\mathrm{h})$ & $\mathrm{pH}$ \\
\hline 0 & 4.35 \\
1.5 & 4.50 \\
3 & 4.71 \\
4 & 5.01 \\
5 & 5.12 \\
6 & 5.87 \\
12 & 6.69 \\
\hline
\end{tabular}

limited to $\pm 3 \mathrm{~Hz}$ using a commercial pneumatic control unit. Chemical shifts were externally referenced to $85 \%$ phosphoric acid and TMS for ${ }^{31} \mathrm{P}$ and ${ }^{1} \mathrm{H}$, respectively. The ${ }^{31} \mathrm{P}$ MAS spectra were measured at a spin rate of $10 \mathrm{kHz}$ and with $70 \mathrm{kHz}$ proton decoupling. An exponential window function of $20 \mathrm{~Hz}$ line broadening was applied to each FID before the Fourier transformation.

The ${ }^{31} \mathrm{P}\left\{{ }^{1} \mathrm{H}\right\} \mathrm{CP}$ heteronuclear correlation (HETCOR) spectra were measured at a spin rate of $10 \mathrm{kHz}$. During the contact time $(2.5 \mathrm{~ms})$, the ${ }^{1} \mathrm{H}$ nutation frequency was set equal to $50 \mathrm{kHz}$ and that of ${ }^{31} \mathrm{P}$ was ramped through the Hartmann-Hahn matching sideband. ${ }^{48}$ Quadrature detection in the $F_{1}$ dimension was achieved by the hypercomplex approach. Typically, for each $t_{1}$ increment, 32 transients were accumulated and a total of 50 increments were done at steps of $100 \mu \mathrm{s}$.

The ${ }^{31} \mathrm{P}\left\{{ }^{1} \mathrm{H}\right\}$ Lee-Goldburg CP (LG-CP) spectra were measured at a spin rate of $10 \mathrm{kHz}$. During the contact time, the ${ }^{1} \mathrm{H}$ nutation frequency and the resonance offset were set equal to 50 and $35.35 \mathrm{kHz}$, respectively, to fulfill the Lee-Goldburg irradiation condition. The ${ }^{31} \mathrm{P}$ DQ experiments were carried out under the MAS frequency of $10 \mathrm{kHz}$ based on the so-called HSMAS-DQ technique. ${ }^{35,49}$ To prepare the initial spin system identically for each transient, a saturation comb was applied prior to the recovery delay $(8 \mathrm{~s})$. During the DQ excitation and reconversion periods, the ${ }^{31} \mathrm{P} \pi / 2$ and $\pi$ pulses were set to 5 and $30 \mu \mathrm{s}$ long, respectively. The $\pi$ pulse trains were phase cycled according to the XY-8 scheme. ${ }^{50}$ The DQ reconversion period was set equal to the excitation period. Proton decoupling was set to $85 \mathrm{kHz}$ during the DQ excitation/reconversion periods. A more detailed description of the experiment was given elsewhere. ${ }^{35}$

\section{Results and Analyses}

A. SEM. The $\mathrm{pH}$ values of the reaction mixture at different times are summarized in Table 1. Referring to the SEM images of our sample series shown in Figure 1, the crystals of the 1.5-h sample are poorly faceted rectangular plates. The bladelike crystal of the 3-h sample is the characteristic morphology of OCP. As the $\mathrm{pH}$ value of the reaction mixture rose to 5.01, at which the 4-h sample was collected, notches were found on the rectangular OCP crystals. Formation of slits along the $c$ axis was also observed in previous studies. ${ }^{16,31}$ The 12 -h sample was collected at a $\mathrm{pH}$ of 6.69 , and the crystals are mainly hexagonal and rod shaped.

B. TEM and ED. The 3-h, 6-h, and 12-h samples were characterized by TEM and ED. The long edge of the bladelike OCP crystal is found to be along the $c$ axis. The selected-area electron diffraction (SAED) patterns of the 3-h and 12-h samples can be assigned to the reflections along the [110] zone axis of OCP and the [210] zone axis of HAp, respectively. Consequently, the SAED patterns of the two samples can serve as a reference for the analysis of the SAED pattern of the 6-hr sample. Figure $2 \mathrm{a}$ shows the TEM image of the 6-h sample. Consistent with what has been observed in the SEM image, the

(48) Metz, G.; Wu, X. L.; Smith, S. O. J. Magn. Reson. A 1994, 110, 219.

(49) Oyler, N. A.; Tycko, R. J. Phys. Chem. B 2002, 106, 8382.

(50) Gullion, T.; Baker, D. B.; Conradi, M. S. J. Magn. Reson. 1990, 89, 479. bladelike crystal splits along its long edge. Referring to Figure $2 \mathrm{~b}$, some diffraction spots of the SAED pattern of the notch area can be indexed to the reflections along the [210] zone axis of HAp and the others can be indexed to the [110] zone axis of OCP. Therefore, in the notch area, the $c$ axes of both HAp and OCP in the 6-h sample are aligned along the elongated side of the bladelike crystal. ${ }^{28,29}$ This alignment of the crystallographic $c$ axes of OCP and HAp is an important structural constraint for the OCP to HAp transformation (vide infra).

C. XRD. As an independent approach to identify the crystalline phases of our samples, the XRD patterns were measured (Figure 3). Any reflections at $2 \theta=4.9^{\circ}, 10.8^{\circ}$, and $13.1^{\circ}$ can be considered as the characteristic peaks of OCP (Joint Committee for Powder Diffraction Studies, JCPDS, 44-0778), HAp (JCPDS 24-0033), and monetite (JCPDS 09-0080), respectively. For the 1.5 -h sample, the absence of the reflections at $2 \theta=10.8^{\circ}$ and $13.1^{\circ}$ indicates that the sample is pure OCP. For the 3-h sample, a trace amount of monetite is present in addition to OCP. Note that the two characteristic reflections of brushite $\left(\mathrm{CaHPO}_{4} \cdot 2 \mathrm{H}_{2} \mathrm{O}\right)$ at $2 \theta=11.6^{\circ}$ and $23.4^{\circ}$ are not found in our samples (JCPDS 11-0293). The characteristic peak of HAp $\left(2 \theta=10.8^{\circ}\right)$ becomes observable for the 4-h sample. For the samples with a longer reaction time, the HAp characteristic peak becomes more prominent at the expense of those of OCP and monetite. Eventually, the 12-h sample is pure HAp. Because the structures of OCP and HAp are intimately related, the coexistence of the OCP and HAp characteristic diffraction peaks in the 4-h, 5-h, and 6-h samples does not necessarily imply the presence of a mixture of the crystallites of pure OCP and HAp phases. In fact, the existence of interlayered mixtures between OCP and HAp has been demonstrated in a "single crystal". 51,52 As summarized in Table 2, the lattice parameters of the 3-h and 5-h samples are approximately the same but both the $a$ and $b$ axes of the OCP lattice have a significant increase in the 4-h sample. A detailed assignment of the selected XRD pattern is given in the Supporting Information (Figure S1).

D. Solid-State NMR. Figure 4 shows the ${ }^{31} \mathrm{P}$ MAS spectra measured for our sample series, together with the spectral assignment we made earlier. ${ }^{34}$ The six phosphorus sites are categorized into two groups, viz., $\mathrm{PO}_{4}{ }^{3-}(\mathrm{P} 1, \mathrm{P} 3, \mathrm{P} 2, \mathrm{P} 4)$ and $\mathrm{HPO}_{4}{ }^{2-}$ (P5, P6). P1 is rather isolated from the water molecules, and $\mathrm{P} 3$ is hydrogen bonded to one of the $\mathrm{HPO}_{4}{ }^{2-}$ groups. P2 and $\mathrm{P} 4$ are in close vicinity to the water molecule whose oxygen atom corresponds closely to the $\mathrm{OH}$ site in HAp. The phosphorus groups at $\mathrm{P} 2, \mathrm{P} 4$, and $\mathrm{P} 6$ are at about the same distance from the $\mathrm{OH}$ site. It is quite clear that the samples of reaction times from 1.5 to $5 \mathrm{~h}$ contain mainly the OCP species. The crystallinity is rather poor for the 1.5-h sample because the corresponding signals have larger line widths than those for the 3-h sample. This observation is consistent with our SEM data, in which the crystals of the 1.5-h sample are found to be poorly faceted. Presumably, there are a lot of excess water molecules in the 1.5-h sample which cannot be accommodated in the OCP lattice. Judging from the NMR spectrum, the molecular structure of the 3-h sample is closest to that of pure OCP, although a trace amount of monetite is present in it. The ${ }^{31} \mathrm{P}$ chemical shift data and the assignment of the 3-h sample are summarized in

(51) Brown, W. E.; Schroeder, L. W.; Ferris, J. S. J. Phys. Chem. 1979, 83, 1385.

(52) Brown, W. E.; Smith, J. P.; Lehr, J. R.; Frazier, A. W. Nature (London) 1962, 196, 1050 . 
(a)

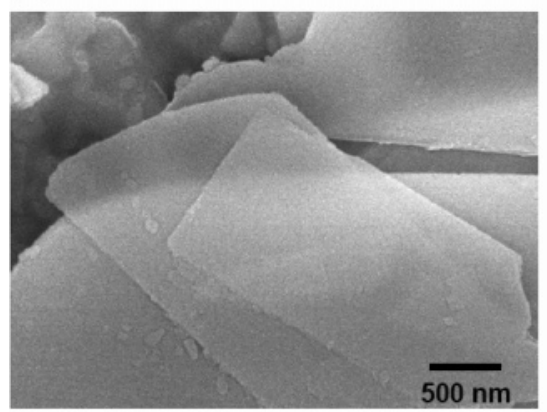

(c)

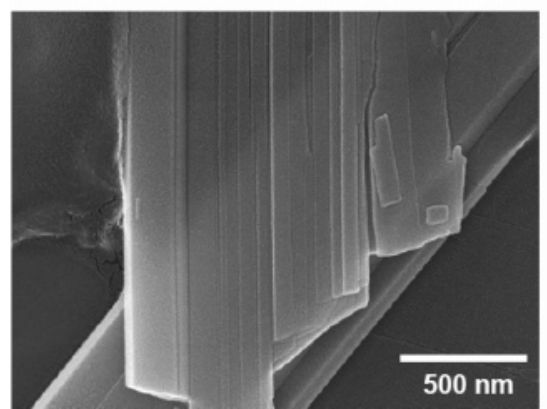

(b)

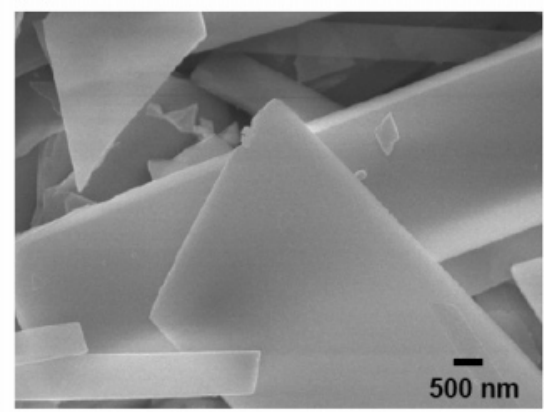

(d)

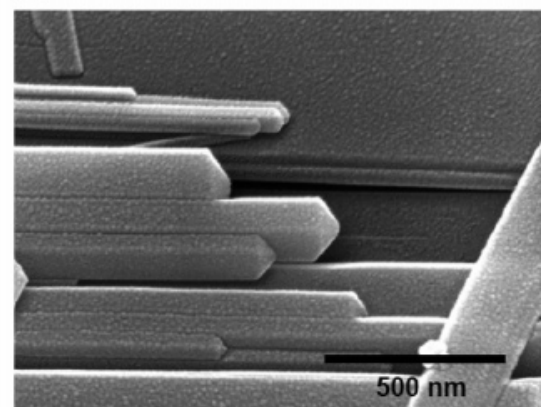

Figure 1. SEM images of the calcium phosphate precipitate collected at different reaction times: (a) $1.5 \mathrm{~h}$; (b) $3 \mathrm{~h}$; (c) $4 \mathrm{~h}$; (d) $12 \mathrm{~h}$.

Table 3. As the reaction time proceeds to $6 \mathrm{~h}$, a significant change in the signal pattern is observed, showing that the system has undergone a considerable change in the phosphorus environments. Note that the 6-h spectrum is not a superposition of the 3-h (OCP) and 12-h (HAp) spectra. That is, the 6-h sample does not have two kinds of crystallites corresponding to pure OCP and HAp phases. Therefore, reprecipitation is unlikely the predominant transformation mechanism. The structural transition is essentially completed after $12 \mathrm{~h}$ because the spectra of the 12-h and 96-h samples are identical. The spectrum of the 12-h sample shows a single peak positioned at $3.2 \mathrm{ppm}$ and is readily assigned to the $\mathrm{PO}_{4}{ }^{3-}$ group of HAp. ${ }^{53}$ This series of MAS spectra demonstrates that the transformation of OCP to HAp is a gradual process and is best described as a relocation of the OCP phosphate groups.

${ }^{31} \mathbf{P}\left\{{ }^{1} \mathbf{H}\right\}$ Heteronuclear Correlation (HETCOR). To obtain a better spectral resolution, we measured the ${ }^{31} \mathrm{P}\left\{{ }^{1} \mathrm{H}\right\}$ HETCOR spectra for the sample series. Figure 5 shows the HETCOR spectra of the 1.5-h, 3-h, and 5-h samples. Considering the spectrum of the $1.5-\mathrm{h}$ sample, the ${ }^{31} \mathrm{P}$ peak at $-0.2 \mathrm{ppm}(\mathrm{P} 5$ and P6) is correlated to the ${ }^{1} \mathrm{H}$ signals at 5.5 and $13.3 \mathrm{ppm}$, which have been assigned to the structural water and the acidic proton of the $\mathrm{HPO}_{4}{ }^{2-}$ ions. ${ }^{54}$ Note that a relatively weak correlation peak can also be identified for the ${ }^{1} \mathrm{H}$ signal at 0.2 ppm and the P2 signal at $3.3 \mathrm{ppm}$. This correlation peak is a well-known marker for apatite-like structures. ${ }^{36,37,42,54}$ For the spectrum of the 3-h sample, an additional set of cross-peaks denoted by a rectangle is observed, which is due to the $\mathrm{HPO}_{4}{ }^{2-}$ group of monetite. ${ }^{32,34,54}$ As the reaction time proceeds further, the corresponding HETCOR spectra show that the intensity of the apatite component increases at the expense of the monetite and the OCP signals (see Figure S2 of the Supporting Informa-

(53) Tropp, J.; Blumenthal, N. C.; Waugh, J. S. J. Am. Chem. Soc. 1983, 105, 22.

(54) Yesinowski, J. P.; Eckert, H. J. Am. Chem. Soc. 1987, 109, 6274. tion). Overall, our HETCOR data are in complete agreement with the XRD results.

${ }^{31} \mathbf{P}\left\{{ }^{1} \mathbf{H}\right\}$ Lee-Goldburg Cross-Polarization. Recently, it has been shown that the LG homonuclear decoupling technique can be combined with $\mathrm{CP}$ to achieve polarization transfer with efficient suppression of ${ }^{1} \mathrm{H}-{ }^{1} \mathrm{H}$ spin diffusion. ${ }^{43,44}$ Therefore, it is possible to investigate the hydration state of the individual phosphorus species by measuring the LG-CPMAS spectra with variable contact times. The intensities of the four resolved ${ }^{31} \mathrm{P}$ signals (P1, P2/P4, P3, P5/P6) were fitted by the following equation as a function of contact time $\left(\tau_{\mathrm{CP}}\right)$ and relaxation time $\left(T_{1 \rho}^{\mathrm{H}}\right)$ :

$$
I(t)=I_{0}\left\{1-\exp \left(-t / \tau_{\mathrm{CP}}\right)\right\} \exp \left(-t / T_{1 \rho}^{\mathrm{H}}\right)
$$

Typical fitting of the raw data was shown in Figure S3 of the Supporting Information. The parameters $\tau_{\mathrm{CP}}$ and $T_{1 \rho}^{\mathrm{H}}$ obtained for our sample series were shown in Figure 6, which do not show any strong correlation in the nonlinear least-squares fittings. Considering the data of the 1.5-h sample, the relative $\tau_{\mathrm{CP}}$ and $T_{1 \rho}^{\mathrm{H}}$ values are consistent with the facts that (i) P5 and $\mathrm{P} 6$ are $\mathrm{HPO}_{4}{ }^{2-}$ species; (ii) P3 is hydrogen bonded to one of the $\mathrm{HPO}_{4}{ }^{2-}$ groups; (iii) $\mathrm{P} 2$ and $\mathrm{P} 4$ are in close vicinity to neighboring water molecules; and (iv) P1 is rather isolated from all the water molecules (distance $>4.6 \AA$ ).${ }^{27}$ For the 3-h sample, the $\tau_{\mathrm{CP}}$ and $T_{1 \rho}^{\mathrm{H}}$ values of the $\mathrm{PO}_{4}{ }^{3-}$ species increase considerably. Together with the fact that the ${ }^{31} \mathrm{P}$ signal line widths are narrower for the 3-h sample, it can be surmised that the crystallinity of the 3-h sample improves when those excess water molecules are expelled from the structure. For the 4-h and 5-h samples, the $\tau_{\mathrm{CP}}$ values of all the $\mathrm{PO}_{4}{ }^{3-}$ species decrease significantly and then increase again. An opposite trend was observed for the $T_{1 \rho}^{\mathrm{H}}$ data. This interesting variation of the $\tau_{\mathrm{CP}}$ and $T_{1 \rho}^{\mathrm{H}}$ values of the $\mathrm{PO}_{4}{ }^{3-}$ species is possibly due to a change in the hydration level of the phosphate ions. As the $\mathrm{pH}$ of the 
(a)

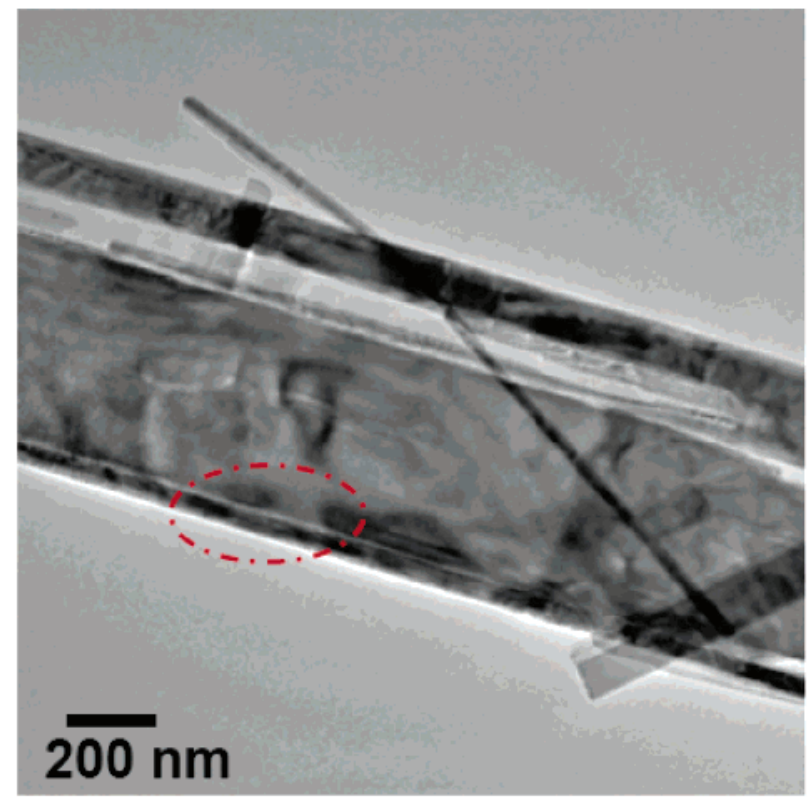

(b)

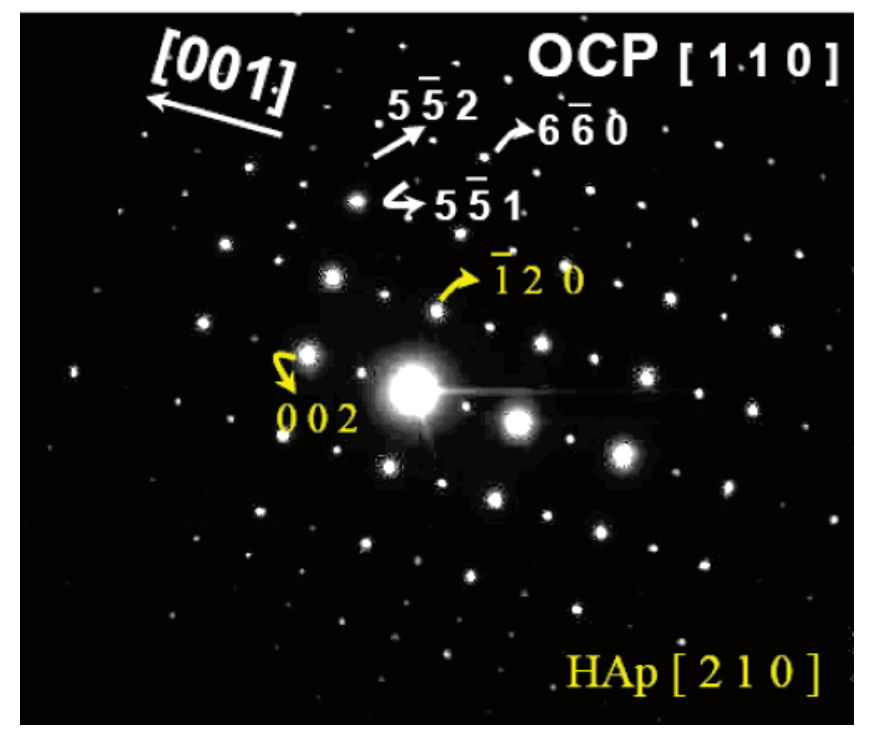

Figure 2. (a) TEM image and (b) SAED pattern measured for the 6-h sample. The SAED pattern was taken from the ellipsoidal region highlighted in (a).

reaction mixture increases continuously because of the decomposition of urea, the equilibrium of the following reaction shifts to the right:

$$
\mathrm{HPO}_{4}{ }^{2-}+\mathrm{OH}^{-}=\mathrm{PO}_{4}{ }^{3-}+\mathrm{H}_{2} \mathrm{O}
$$

When the $\mathrm{pH}$ value reaches 5.01, at which we collect the 4-h sample, more water molecules will enter the hydration layer of the OCP structure, resulting in the formation of straight notches along the $c$ axis for the 4-h sample (Figure 1). Indeed, the analysis of the XRD patterns shows that both the $a$ and $b$ axes of the OCP unit cells increase considerably for the 4-h sample. Our interpretation is also in line with the ${ }^{31} \mathrm{P}$ MAS spectrum of the 4-h sample, where the line widths of the P1 and P2/P4 signals are somewhat broadened because of an increase in

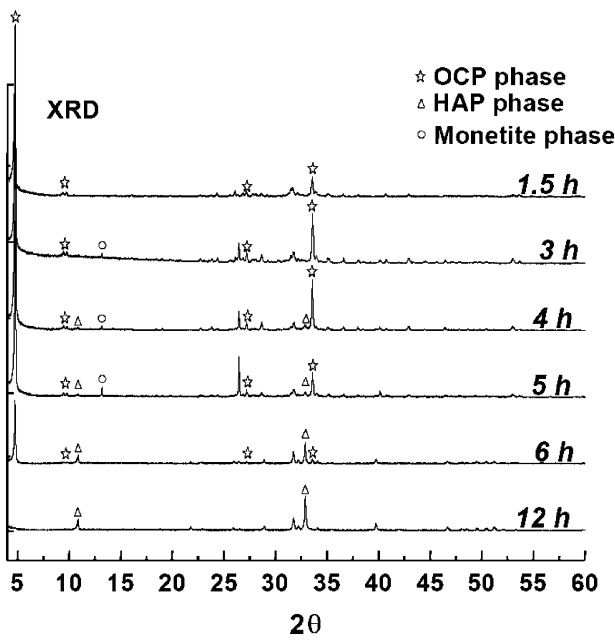

Figure 3. XRD patterns measured for samples obtained at different reaction times.

Table 2. Summary of the Lattice Parameters Determined for Different Samples

\begin{tabular}{lllll}
\hline sample & \multicolumn{1}{c}{$a[\AA]$} & \multicolumn{1}{c}{$b[\AA]$} & $c[\AA]$ & cell volume $\left[\AA^{3}\right]$ \\
\hline $1.5-\mathrm{h}$ & $19.7316(8)^{a}$ & $9.5615(3)$ & $6.8508(2)$ & $1224.96(7)$ \\
3-h & $19.7049(9)$ & $9.5525(4)$ & $6.8447(2)$ & $1222.59(8)$ \\
4-h & $19.8456(38)$ & $9.5941(17)$ & $6.8445(9)$ & $1232.03(32)$ \\
$5-\mathrm{h}$ & $19.7017(10)$ & $9.5490(5)$ & $6.8471(2)$ & $1222.57(9)$ \\
\hline
\end{tabular}

$a$ The bracketed values are error estimations.

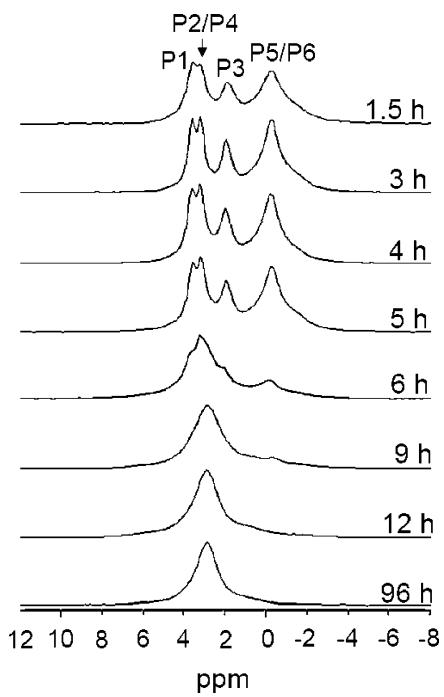

Figure 4. ${ }^{31} \mathrm{P}$ MAS spectra measured for our sample series at $10 \mathrm{kHz}$ spinning frequency and $7.05 \mathrm{~T}$.

Table 3. ${ }^{31} \mathrm{P}$ Chemical Shift Data and the Assignment of the 3-h Sample

\begin{tabular}{cccll}
\hline & ${ }^{31} \mathrm{P} \delta_{\text {iso }}[\mathrm{ppm}]$ & intensity ratio & & \\
\hline P1 & 3.7 & 1 & $\mathrm{PO}_{4}{ }^{3-}$ & apatite layer \\
P2, P4 & 3.3 & 1 & $\mathrm{PO}_{4}{ }^{3-}$ & apatite layer \\
P3 & 2.0 & 1 & $\mathrm{PO}_{4}{ }^{3-}$ & interface \\
P5, P6 & -0.2 & 3 & $\mathrm{HPO}_{4}{ }^{2-}$ & hydration layer \\
\hline
\end{tabular}

structural disorder. Consequently, the water molecules in the 4-h sample will cause a decrease in the $\tau_{\mathrm{CP}}$ value because we have more water molecules surrounding the $\mathrm{PO}_{4}{ }^{3-}$ species. On the other hand, $T_{1 \rho}^{\mathrm{H}}$ is sensitive to molecular motions in the frequency range around the effective LG irradiation field (ca. $61 \mathrm{kHz}){ }^{55}$ Therefore, as more water molecules enter the OCP 

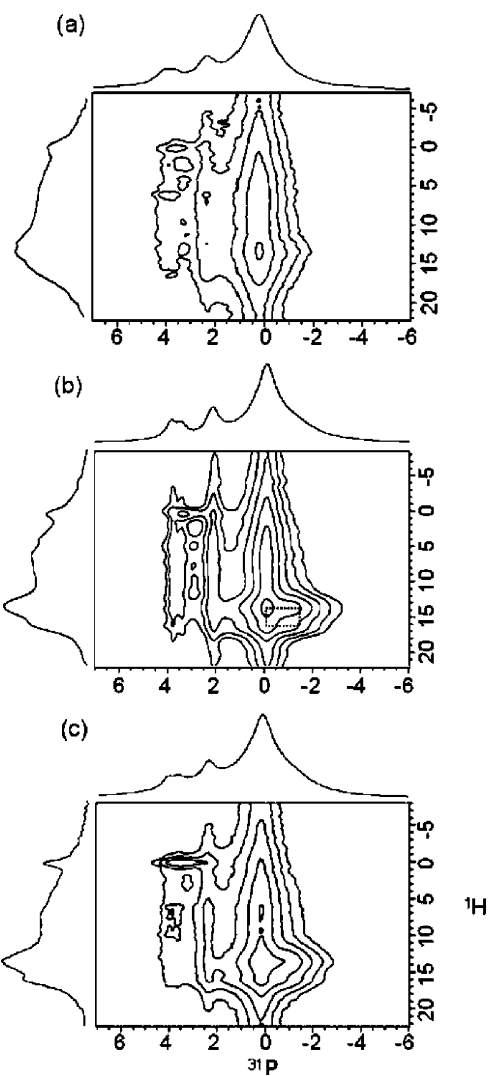

Figure 5. ${ }^{31} \mathrm{P}\left\{{ }^{1} \mathrm{H}\right\}$ HETCOR spectra measured for samples (a) $1.5 \mathrm{~h}$; (b) $3 \mathrm{~h}$; and (c) $5 \mathrm{~h}$.
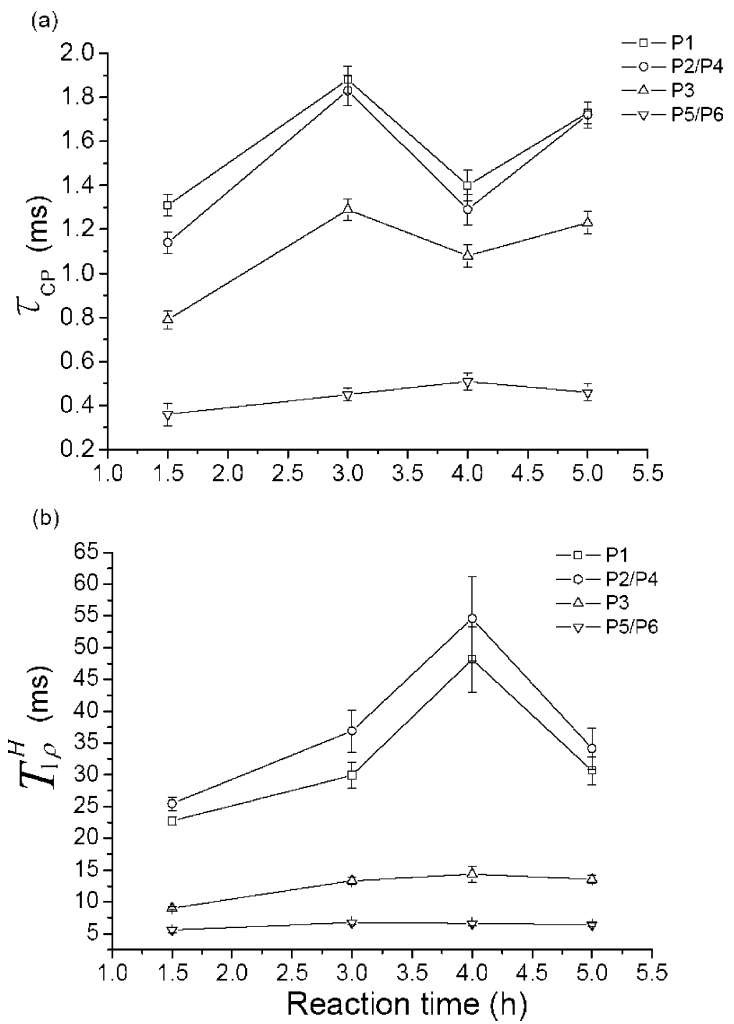

Figure 6. LG-CP parameters obtained for our sample series: (a) $\tau_{\mathrm{CP}}$; (b) $T_{1 \rho}^{\mathrm{H}}$.

hydration layer, the more frequent collision among the water molecules, which should be much faster than $61 \mathrm{kHz}$, will cause an increase in $T_{1 \rho}^{\mathrm{H}}$. As the $\mathrm{pH}$ of the reaction mixture increases (a)
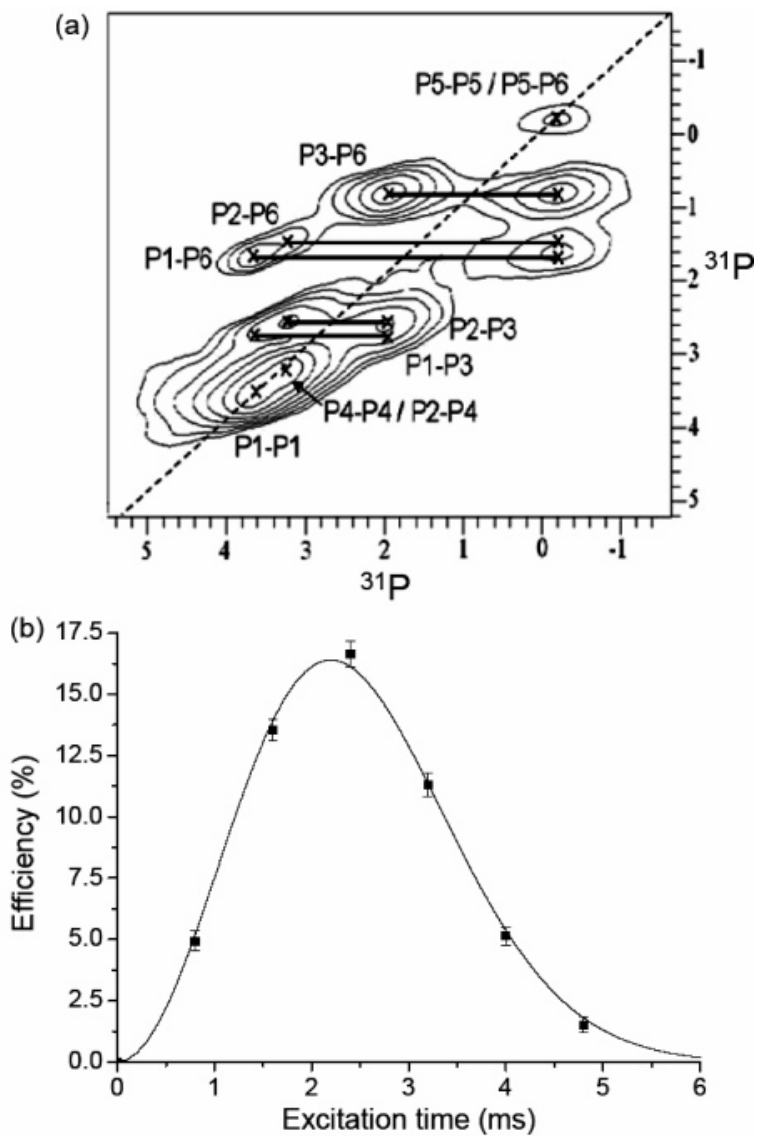

Figure 7. (a) ${ }^{31} \mathrm{P} \mathrm{DQ}$ correlation spectrum measured for the $1.5-\mathrm{h}$ sample. The DQ excitation time was set to $3.2 \mathrm{~ms}$. (b) Fitting of the modulation of the normalized P3-P6 DQ signals (excitation efficiency) as a function of excitation time.

further, the excessive water molecules in the hydration layer start to diffuse out of the OCP structure, resulting in an increase in $\tau_{\mathrm{CP}}$ and a decrease in $T_{1 \rho}^{\mathrm{H}}$ for the 5-h sample. Accordingly, the cell dimensions of the 5-h sample become comparable to those of the 3-h sample (Table 2). Note that the variation in the $\mathrm{CP}$ dynamics of $\mathrm{P} 3$ is not as dramatic as those of $\mathrm{P} 1, \mathrm{P} 2$, and $\mathrm{P} 4$ because $\mathrm{P} 3$ is hydrogen bonded to the acidic proton of $\mathrm{P} 6 .^{27}$

${ }^{31} \mathbf{P}-{ }^{31} \mathbf{P}$ Double-Quantum NMR. When two or more nuclear spins are in close proximity, they become coupled through the homonuclear magnetic dipole-dipole interaction. The magnitude of such an interaction is inversely proportional to the third power of the internuclear distance. The so-called DQ coherence is a concerted evolution of coupled spins. The two-dimensional ${ }^{31} \mathrm{P}$ DQ spectrum of the 1.5-h sample is shown in Figure 7a, where there are eight sets of auto- and cross-correlation peaks assigned to the OCP signals. Surprisingly, in the DQ spectra measured for the 3-h, 4-h, and 5-h samples, we do not observe any correlation peaks due to monetite (see Figure S4 of the Supporting Information). Referring to Figure 7a, by varying the DQ excitation and reconversion periods systematically, one can fit the intensities of the correlation peaks as a function of the excitation time based on the following equation ${ }^{42}$

$$
I\left(\tau_{\text {exe }}\right)=A \tau_{\text {exe }}^{2} \exp \left\{-\tau_{\text {exe }}^{2} / B\right\}
$$

(55) Freeman, R. Spin Choreography: Basic Steps in High-Resolution NMR; Oxford University Press: New York, 1998. 


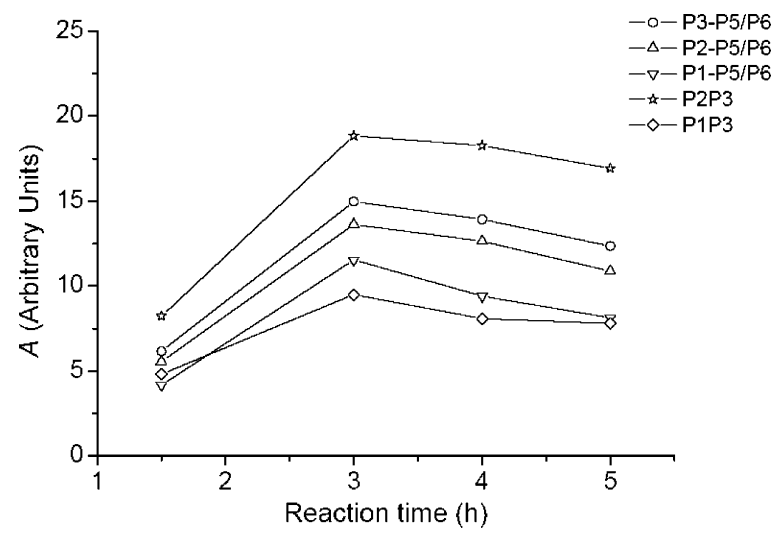

Figure 8. Plot of the parameter $A$ extracted for the cross-correlation peaks. The sizes of the symbols are larger than the error bars.

In the above equation, the build up of the DQ signals is described by a parabolic function ${ }^{56,57}$ and the decay of the DQ signals is approximated by a Gaussian function. ${ }^{58}$ Figure $7 \mathrm{~b}$ illustrates such a fit for the P3-P6 DQ signals of the 1.5-h sample, in which the signal intensities had been normalized with respect to the MAS signals measured under identical conditions (spinning frequency, saturation comb, and recycle delay). ${ }^{35}$ In principle, the parameter $A$ can be used to determine the van Vleck's second moment of the coupled spins, whose magnitude depends on both the number of interacting spins and the internuclear distances. ${ }^{59}$ However, the quantification of the second moment in the present study is not warranted because of the different efficacy of proton decoupling for different phosphorus species. Nevertheless, the variation of the parameter $A$ should reflect the same variation in the second moment for a particular DQ signal, provided that the efficacy of the proton decoupling remains approximately the same. On the other hand, because the values of the parameter $B$ are affected by both the ${ }^{31} \mathrm{P}$ spin-spin relaxation times and the spatial arrangement of the interacting phosphorus species, it is difficult to interpret the data trend unequivocally. The raw data of parameters $A$ and $B$ are tabulated in the Supporting Information (Table S1).

Figure 8 summarizes the values of the parameter $A$ extracted for the cross-correlation peaks of our sample series. As expected, the $A$ values for the 1.5 -h sample are attenuated significantly due to insufficient proton decoupling. For the 3-h sample, the following data trend is parallel to what we expected from the calculated van Vleck's second moment:

$$
\begin{array}{ccccc}
A_{\mathrm{P} 2-\mathrm{P} 3}> & A_{\mathrm{P} 3-\mathrm{P} 5 / \mathrm{P} 6}> & A_{\mathrm{P} 2-\mathrm{P} 5 / \mathrm{P} 6}> & A_{\mathrm{P} 1-\mathrm{P} 5 / \mathrm{P} 6}> & A_{\mathrm{P} 1-\mathrm{P} 3} \\
(3.19) & (1.84) & (1.08) & (0.46)
\end{array}
$$

where the bracketed data denote the corresponding second moments $\left(\times 10^{6} \mathrm{rad}^{2} / \mathrm{s}^{2}\right)$ calculated on the basis of the X-ray structural data. As revealed in Figure 6, the efficacy of proton decoupling should be very similar for the 3-h and 5-h samples. Therefore, it is legitimate to calculate the percentage change of their $A$ values corresponding to the same DQ coherence and compare the results with what we expected from our model for the OCP transformation (vide infra).

(56) Bertmer, M.; Eckert, H. Solid State Nucl. Magn. Reson. 1999, 15, 139.

(57) Gunne, J.; Eckert, H. Chem.-Eur. J. 1998, 4, 1762.

(58) Engelsberg, M.; Norberg, R. E. Phys. Rev. B 1972, 5, 3395

(59) Abragam, A. Principles of Nuclear Magnetism; Clarendon Press: Oxford, 1961.
E. Computer-Assisted Lattice Matching. It has been well established that the apatitic layer of OCP is structurally very similar to HAp. Indeed, our TEM/ED results are consistent with the scenarios that the $c$ axes of the OCP and HAp unit cells are parallel or antiparallel to one another during the phase transformation. For the OCP to HAp transformation, our NMR data indicate that the transformation is most likely realized by the relocation of the OCP phosphorus groups. Assuming that the phosphorus groups of OCP will take the shortest pathways to migrate to the nearest phosphorus sites of HAp, we attempt to superimpose the HAp lattice onto the OCP lattice and identify the mappings between the OCP phosphorus sites and those HAp sites by computer-assisted lattice matching. We generate two unit cell models, viz., the guest and the host. The guest model contains the Cartesian coordinates of 6 phosphorus atoms in a unit cell of HAp. Although the space group of the HAp lattice is $P 6_{3} / m$, the guest model corresponding to a unit cell along the $[2 \overline{1} \overline{1} 0]_{\text {HAp }}$ and $[\overline{1} 2 \overline{1} 0]_{\text {HAp }}$ axes has a well-defined $c$ direction. The host model contains the coordinates of 96 phosphorus atoms in $2 \times 2 \times 2$ unit cells of OCP. Initially, the crystallographic $c$ axes of both models are aligned in the same direction. The coordinates of the guest lattice are then superimposed onto the host lattice rotationally and translationally. The rotation is about the $c$ axis at steps of one degree, and the translations are along three orthogonal axes at steps of $0.5 \AA$. The mean-square deviations $\left(\chi^{2}\right)$ between the HAp phosphorus sites and the corresponding nearest OCP sites are calculated for each matching step. On the basis of the results of minimum $\chi^{2}$, each HAp site can be mapped to one of the six nonequivalent OCP sites. A more graphical description is given in the Supporting Information. Consequently, we label all the phosphorus sites in the HAp lattice with the name tags of the six nonequivalent phosphorus sites in OCP. On the basis of the HAp lattice, the van Vleck's second moments arising from, say, P2-P3 are calculated using the following formula: ${ }^{59}$

$$
M_{2}=\frac{3}{5} \gamma^{4} \hbar^{2} I(I+1) \sum_{j} \frac{1}{r_{j}^{6}}
$$

The obtained value $\left(1.45 \times 10^{6} \mathrm{rad}^{2} / \mathrm{s}^{2}\right)$ is then compared with the one calculated on the basis of the OCP lattice $\left(3.19 \times 10^{6}\right.$ $\left.\operatorname{rad}^{2} / \mathrm{s}^{2}\right)$. Their ratio is calculated as the percentage of the latter (45\%). Similarly, we obtained the ratios corresponding to the $M_{2}$ values of P1-P3, P1-P5/P6, and so on (see Table S4 of the Supporting Information). All the calculations were then repeated for opposite alignment of the crystallographic $c$ axes of the guest and host models. Provided that the phosphorus sites of OCP will take the shortest pathways to migrate to the nearest phosphorus sites of HAp, the calculated ratios of the second moments should be very similar to the ratios of the experimental $A$ values of $\mathrm{P} 2-\mathrm{P} 3$ measured for the 3-h and 5-h samples. Figure 9 plots the calculated ratios vs the ratios of the experimental $A$ values. Note that a perfect agreement between the calculated and experimental ratios is not expected because the OCP to HAp transformation is not yet completed for the 5-h sample. Overall, our DQ experimental data are more consistent with the scenario in which the crystallographic $c$ axes of OCP and HAp are in opposite direction at the OCP-HAp interface. In addition, the lattice-matching results for the antiparallel alignment of the $c$ axes show that during the structural transformation the $b$ axis 


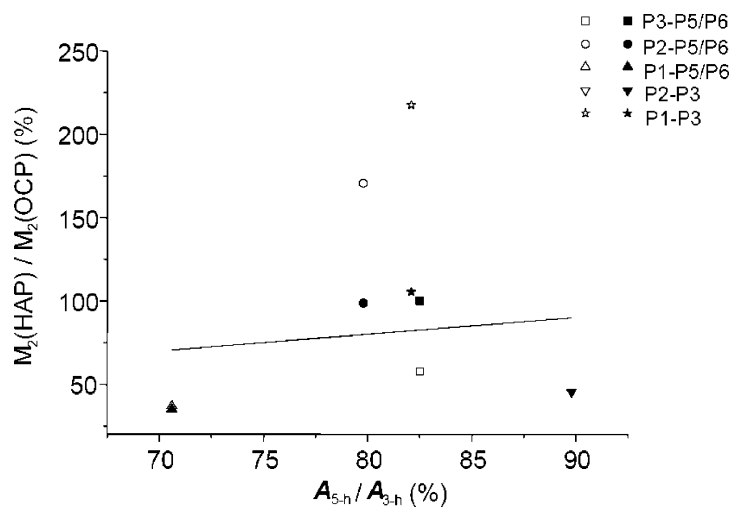

Figure 9. Plot of the calculated ratios of the second moments of the OCP and the matched HAp lattice vs the ratios of the experimental $A$ values measured for the 3-h and 5-h samples. The filled and open symbols denote the calculated data for antiparallel and parallel alignments, respectively, of the crystallographic $c$ axes of OCP and HAp at the interface. The solid line denotes perfect agreement.

of OCP is parallel to the $[2 \overline{1} \overline{1} 0]_{\text {HAp }}$ axis of HAp. In other words, the interface between OCP and HAp occurs parallel to the $b c$ plane of OCP, as has been established in the literature. ${ }^{51}$

\section{Discussion}

Double-Quantum NMR in Multiple-Spin Systems. DQ NMR spectroscopy under magic angle spinning has been the major research area in the solid-state NMR community for many years. Since the pioneering work of Tycko, ${ }^{60}$ numerous pulse sequences designed for DQ NMR have been reported in the literature ${ }^{61-64}$ Our previous work illustrates that the excitation of DQ coherence is inherently difficult in multiple-spin systems because of the dephasing effect of other passive spins. ${ }^{35}$ It has also been shown that distance measurement by DQ NMR spectroscopy in homonuclear spin systems is practical only if the two-spin approximation holds. ${ }^{65}$ Nevertheless, we have demonstrated here that it remains possible to employ DQ NMR spectroscopy to monitor the change of the spatial arrangement of interacting spins, provided that an adequate structural model is constructed to interpret the variation of the DQ signal intensities. In this work, our computer-assisted lattice matching provides such a model in which the structural constraint obtained by SAED measurements is incorporated. We note in passing that Levitt and co-workers have successfully employed solidstate ${ }^{29} \mathrm{Si}$ DQ dipolar recoupling NMR to help elucidate the crystal structures of siliceous zeolite model compounds by measuring distance-dependent dipolar interactions between naturally abundant ${ }^{29} \mathrm{Si}$ nuclei in the zeolite frameworks, where the two-spin approximation clearly holds for two interacting ${ }^{29}$ Si nuclei. ${ }^{66,67}$

OCP to HAp Transition. In an early study by Eanes and Meyer, the nature of the phase changes occurring in spontaneously precipitated amorphous calcium phosphate (ACP) was studied under physiological conditions. ${ }^{11}$ On the basis of the

(60) Tycko, R.; Dabbagh, G. Chem. Phys. Lett. 1990, 173, 461

(61) Tycko, R. Annu. Rev. Phys. Chem. 2001, 52, 575.

(62) Baldus, M. Prog. Nucl. Magn. Reson. Spectrosc. 2002, 41, 1.

(63) Luca, S.; Heise, H.; Baldus, M. Acc. Chem. Res. 2003, 36, 858.

(64) Schnell, I. Prog. Nucl. Magn. Reson. Spectrosc. 2004, 45, 145.

(65) Gunne, J. J. Magn. Reson. 2003, 165, 18.

(66) Brouwer, D. H.; Darton, R. J.; E. M. R.; Levitt, M. H. J. Am. Chem. Soc. 2005, 127, 10365

(67) Brouwer, D. H.; Kristiansen, P. E.; Fyfe, C. A.; Levitt, M. H. J. Am. Chem. Soc. 2005, 127, 542 measured ion concentrations and the $\mathrm{Ca} / \mathrm{P}$ ratio, it was concluded that the ACP precipitate would first transform into an OCPlike phase which subsequently hydrolyzed into apatite. This result is consistent with the Ostwald-Lussac law of stages, which states that under conditions of sequential precipitation the initial phase formed is the one with the highest solubility followed by other crystalline phases in order of decreasing solubility. ${ }^{1}$ For our in vitro system, we also observe the coprecipitation of monetite at $100{ }^{\circ} \mathrm{C}$. In the thermodynamic aspect, the coprecipitation of monetite is not unexpected because the solubility product of brushite, the hydrated form of monetite, is very similar to that of OCP at a $\mathrm{pH}$ around $4.71-5.12 .{ }^{68}$ The detection of coprecipitation of monetite by the HETCOR NMR technique is of great interest in the study of biomineralization because diffraction techniques are unlikely to distinguish between HAp, OCP, or monetite when the crystallites are thinner than $10 \mathrm{~nm}$, as reported for bone..$^{52}$ On the basis of the similarity of the calcium phosphate chains present in both the OCP and monetite structures, it has been speculated that the formation of an intracrystalline mixture of OCP and monetite occurs by direct precipitation or by hydrolysis of OCP. ${ }^{52}$ From our NMR data, we have no direct evidence for the existence of such an intracrystalline mixture. The absence of the monetite ${ }^{31} \mathrm{P}$ signals in the DQ spectra of our 3-h, 4-h, and 5-h samples, however, could be explained by the argument that the amount of the monetite phase is too low to give any appreciable DQ signals.

Some years ago, Nelson and co-workers described the OCP to HAp transformation as a simple dehydration process. ${ }^{14}$ Here, we could refine this description further for our in vitro system as follows. The OCP crystals obtained at $1.5 \mathrm{~h}$ contain a lot of structural waters, rendering the crystallinity rather poor. The amorphous character of the crystals reveals that the formation of OCP crystals is preceded by the precipitation of ACP. When the $\mathrm{pH}$ of the reaction mixture is lower than 4.71 , those water molecules in excess will be eventually driven out of the lattice, resulting in an improvement of the crystallinity. As the $\mathrm{pH}$ increases to around 5, water molecules will reenter the OCP lattice, presumably through the hydration layer of the OCP structure. This reversal in water flow direction is accompanied by a significant lengthening of the crystallographic $a$ and $b$ axes, causing an expansion of the OCP lattice. The "crowded" water molecules in the hydration layer then provide a collisional mechanism for the relocation of the $\mathrm{HPO}_{4}{ }^{2-}$ groups (P5 and P6). Despite the $2.1 \%$ mismatch between the (100) crystal planes of OCP and HAp, the structural stress induced by the movement of P5 and P6 will cause the apatite layers in the bladelike OCP crystals to split across the $b$ axis. The $\mathrm{HPO}_{4}{ }^{2-}$ ions are subsequently deprotonated, and the water molecules of the hydration layers are released to stabilize the structure. Those apatite layers serve as nucleation centers for further crystal growth, leading to the formation of hexagonal HAp rods eventually.

Implication in Biomineralization. To explain the fact that OCP is often found as a central planar defect in synthetic apatite crystals, Nelson and Barry provided thermodynamics arguments to propose that an OCP crystal would not hydrolyze to HAp unless its crystal size is large enough that the high surface free energy of HAp crystals could be compensated by lattice

(68) Heughebaert, J. C.; Nancollas, G. H. J. Phys. Chem. 1984, 88, 2478

6916 J. AM. CHEM. SOC. - VOL. 128, NO. 21, 2006 


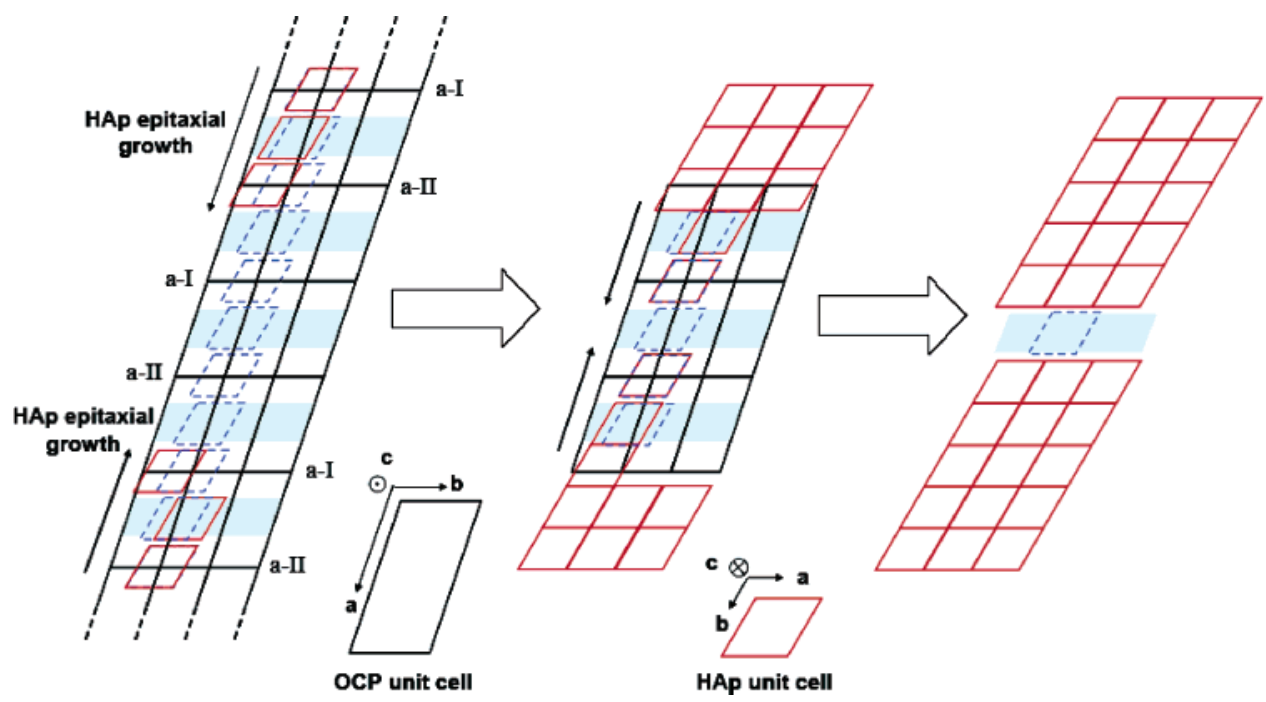

Figure 10. Mechanistic model for CDL formation in biological apatites.

stability. ${ }^{69}$ Therefore, OCP hydrolysis will start on the crystal surface until the diffusion of ions and water molecules is so slow that the residual OCP nuclei are trapped in the central part of the HAp crystal. Although the mechanistic model by Nelson and Barry can explain many features of CDL formation in biological hard tissues, it requires refinement to accommodate more recent findings. In particular, the high-resolution TEM images of dentine crystals measured by Cuisinier and co-workers indicate that the molecular structure of a CDL corresponds closely to the water layer of OCP and that the hydrolysis of OCP in the formation of biological crystals develops along (100) crystal planes. ${ }^{7}$ Together with our NMR data discussed above, we suggest a plausible molecular mechanism for CDL formation described as follows. Referring to Figure 10, initially the phosphate ions of the apatite and hydration layers of the OCP lattice will drift to form HAp sublattices (the dashed parallelograms). These sublattices are contiguous along the OCP $b$ axis, but for clarity, we just show one HAp sublattice per row across the OCP $a$ axis. The apatite layers of OCP are structurally very similar to those of the HAp lattice, and therefore, they are readily available as seeding sites for HAp crystal growth. One can visualize in Figure 10 that the HAp sublattices of neighboring apatite layers, viz., a-I and a-II, are not equivalent in the sense that they cannot be matched along the OCP $b$ axis. As an illustration, we take the a-I and a-II types of HAp sublattices as the top and bottom seeding sites, respectively, for the epitaxial growth of the HAp crystal. The parallelograms in solid red lines depict the translational shifts of the dashed parallelograms as a result of crystal growth. Eventually, the top and bottom HAp lattices will find a significant mismatch at a junction corresponding to the water layer of OCP. The "trapped" OCP water layer has a close resemblance to a CDL in biological apatites. Its formation is not only due to the "coating" by HAp layers as suggested by Nelson and Barry but also most likely due to the inherent lattice mismatch between HAp and OCP. One may surmise that if two neighboring seeding sites are of the same type of HAp sublattice, either a-I or a-II, there will be no mismatch junction in between. Consequently, if there are $N$ seeding sites, the probability of CDL formation would become

(69) Nelson, D. G. A.; Barry, J. C. Anat. Rec. 1989, 224, 265.
$1-(0.5)^{N-1}$. This simple calculation explains the likelihood of multiple CDL formations in synthetic apatites. ${ }^{29}$

According to the crystallographic data and our assignment of the ${ }^{31} \mathrm{P}$ MAS spectrum of the 3-h sample, the peaks positioned at -0.2 (P5, P6), $2.0(\mathrm{P} 3), 3.3(\mathrm{P} 2, \mathrm{P} 4)$, and 3.7 (P1) ppm should have an intensity ratio of $2: 1: 2: 1$, but what has been measured for our OCP sample is $3: 1: 1: 1$ (Table 3). To rationalize the ${ }^{31} \mathrm{P}$ NMR peak intensity ratio, we have previously suggested that some of the $\mathrm{PO}_{4}{ }^{3-}$ groups at the $\mathrm{P} 2$ and $\mathrm{P} 4$ sites are involved in the following transformation to become $\mathrm{HPO}_{4}{ }^{2-}$ ions: ${ }^{34}$

$$
\mathrm{HPO}_{4}{ }^{2-}+\mathrm{OH}^{-}=\mathrm{PO}_{4}{ }^{3-}+\mathrm{H}_{2} \mathrm{O}
$$

In our analysis of the ${ }^{31} \mathrm{P}\left\{{ }^{1} \mathrm{H}\right\}$ LG-CP data, the same mechanism can be applied to explain the intrusion of water molecules into the hydration layers and the deprotonation of the $\mathrm{HPO}_{4}{ }^{2-}$ ions. We believe that this hydrolysis reaction may also take an important role in the formation of biological apatites in bones or teeth.

\section{Conclusion}

In summary, we have established a very useful in vitro system to obtain HAp nanorods with different morphologies by homogeneous precipitation of OCP crystals. Our data obtained by a series of physical techniques, with particular emphasis in solid-state NMR, provide a detailed description of the molecular mechanism of the OCP to HAp transformation. The inherent lattice mismatch between OCP and HAp is suggested to be the mechanistic reason for CDL formation in biological apatites. Furthermore, we find that the hydrolysis reaction of the $\mathrm{PO}_{4}{ }^{3-}$ and $\mathrm{HPO}_{4}{ }^{2-}$ ions is the key chemical reaction for OCP to HAp transformation. Although the scope of this work is limited to the molecular mechanism of the OCP to HAp transition, the solid-state NMR approach established here can be readily applied to the studies of bones and teeth.

Acknowledgment. This work was supported by grants from the National Science Council and the Ministry of Education. We thank Ms. Fang-Wei Hsu for developing the $\mathrm{C}++$ code used in the lattice-matching analysis. We thank Professors $\mathrm{Yu}$ Wang, Shie-Ming Peng, and David Chun-Yi Lu for helpful discussions. 
Supporting Information Available: Detailed indexing of the XRD patterns, ${ }^{31} \mathrm{P}\left\{{ }^{1} \mathrm{H}\right\}$ HETCOR spectra of the 6-h and 12-h samples, typical fitting of the LG-CP raw data, ${ }^{31} \mathrm{P}$ DQ spectra of the 3-h sample and monetite, parameters extracted from the fitting of the DQ excitation and dephasing data, detailed graphical description of the second-moment data calculated based on the computer-assisted lattice matching, and animation of Figure 10. This material is available free of charge via the Internet at http://pubs.acs.org.

JA060336U 